\title{
LA LECTURA Y SUS DIFICULTADES: DISLEXIA EVOLUTIVA
}

\author{
Reseña a cargo del Prof. Dr. Sergio Dansilio
}

Hace un tiempo atrás habíamos pensado con el Prof. Aldo Ferreres, de la Universidad de Buenos Aires, componer un libro que abordase las Alexias en escrituras transparentes, desde la perspectiva teórica de la Neuropsicología Cognitiva que, se ha desarrollado fundamentalmente en el ámbito de las escrituras opacas; siendo discutido su estatuto, en el caso de las escrituras transparentes como el español. LLegamos a escribir dos o tres capítulos y la empresa quedó entonces trunca, por diversas razones, vinculadas en general a nuestros proyectos académicos. Uno de los objetivos era tener -en español- una

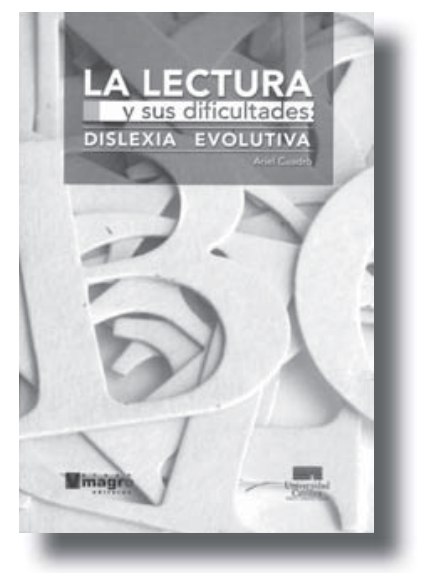
fuente confiable pero también concisa, desde donde acceder a la comprensión de los trastornos lectores, según el modelo que proporcionaba la Psicología Cognitiva del Lenguaje, tanto en lo teórico como en lo metodológico. Se conocieron buenos trabajos realizados en España, sobretodo por el grupo de Cuetos, pero igual creíamos necesario generar en el Río de la Plata una suerte de compendio o de recapitulación, lo suficientemente crítica de un enfoque que continuaba siendo poco conocido -cuando no rechazado (pereza intelectual, prejuicios e inercia mediante) por gran parte de la comunidad académica regional-. Atrás (y adentro), de aquel proyecto, se encontraban los trabajos de investigación que habíamos realizado ambos grupos, algunos publicados, otros presentados en congresos.

Podría entonces ubicar el libro que presenta el Prof. Cuadro y colaboradores dentro de este contexto. Cuando uno dice que se trata de un libro acerca de "La Psicología de la Lectura" parece que hiciera una afirmación trivial; sin embargo, en un medio donde se confunden dimensiones pedagógicas con dimensiones lingüísticas, con dimensiones médico-diagnósticas y de intervención rehabilitadora, cuando no con dimensiones puramente profesionales y de competencia en el mercado laboral, la afirmación deja de ser trivial. Sin embargo, al adentrarnos en los diversos problemas que implica el extraer significados de marcas escritas las cuales refieren a un lenguaje, entonces nos introducimos en la verdadera sustancia por donde hay que categorizar esta publicación que me confiaron para reseñar.

Psicología de la Lectura entonces y de la adquisición del código escrito, más específicamente. Pero hay aquí también una teoría acerca de este dominio cognitivo y de la Psicología del Desarrollo en general, que es el énfasis en el aspecto modular de lo que Fodor llamó -originalmente- los "inferenciales básicos", modularidad que puede rastrearse a etapas muy tempranas de la vida del sujeto. Claro que este libro para nada escamotea la importancia de la incidencia de los factores socio-económicos, ya que conoce ciertamente que una jugada no suprime la otra, el libro se detiene en ello, y creo que termina proporcionando, de esta manera, herramientas más contundentes para entender el problema de las deficiencias lectoras.

El libro cubre claramente una necesidad. Realiza la síntesis justa, tanto en sus aspectos cuantitativos como cualitativos, de una serie de conocimientos a los que solamente podíamos acceder, inglés mediante y luego de extensas redes de consultas bibliográficas, limitando así el alcance de estas teorías a una parte importante de la población académica interesada en el tema y comprometida con aquel. En el año 2000, Margaret Snowling escribió - de referenciapero, no nos dice mucha cosa de qué sucede con los sistemas de escrituras transparentes, y no se conocen traducciones al español. De todas formas, esta publicaciòn se detiene lo justo (empleo deliberadamente la palabra por tercera vez en el párrafo) para considerar cada uno 
de los modelos cognitivos de lectura en forma clara, resalta en el espacio necesario y de manera precisa a la metafonología, presenta una cierta concepción de la dislexia y de sus tipologías, en consonancia con lo que se está haciendo en el mundo y hasta nos deja un capítulo entero asignado a los eventuales programas de intervención. Todo esto, en una extensión lo suficientemente medida como para hacer manejable al libro sin pérdidas, lo cual, constituye todo un arte. Y no de menor entidad es el hecho de que el libro es producto de un equipo, que ha investigado creativa y productivamente sobre el tema, por lo menos diez años, con lo cual el texto se escribe apoyado en la praxis científica, hecho que le otorga la madera de calidad insustituible para poder tallar sus afirmaciones y preguntas.

Volviendo al inicio, cuando proyectamos con la gente de la Universidad de Buenos Aires aquel libro, observábamos una falta regional cierta sobre estos abordajes con respecto a la lectura. La falta se fue manteniendo. También observábamos que el hueco se reproducía en otros países hispanoparlantes de nuestra Latinoamérica y ese hueco también persiste. Vivimos quizá momentos un poco diferentes, donde en el modelaje de la lectura han ingresado discusiones que confrontan estructuras teóricas diversas, asistimos al crecimiento del conexionismo y las técnicas de simulación, y a la combinación con imagenología funcional que han dado las ahora llamadas neurociencias cognitivas. Creo que estas sacudidas más recientes hacen todavía más necesario este libro del Prof. Cuadro y su equipo; lo que convierte esta publicaciòn también en un "acontecimiento" dentro de la Psicología y la Neuropsicología de la Lectura, acontecimiento que nos beneficiará a los que trabajamos en estos temas desde múltiples costados y por lo menos hacia todo el espacio académico hispano-parlante.

Cuadro, Ariel (2010). La lectura y sus dificultades: la dislexia evolutiva. Montevideo: Grupo Magro 